\section{NOTES ON THE PATHOLOGY OF CHOLERA.}

By GEORGE JOHNSON, M.D., F.R.C.P., Physician to King's College Hospital, and Professor of Medicine in King's College.

The Ninth Report of the Medical Officer of the Privy Council contains a paper by Dr. Henry G. Sutton, on the Clinical Characters of the Cholera of 1866, as studied in Miss Sellon's East London Cholera Hospital. I desire now to direct attention to certain points in Dr. Sutton's paper, and to some comments by Mr. Simon, which have reference to the pathology of cholera.

Dr. Sutton states that during the recent epidemic of cholera, he made fifty post mortem examinations, and witnessed many more; and he says that, when the patient had died in collapse, in by far the majority of cases, he found the lungs collapsed and lying back against the spine. They weighed very much less than normal, often half as heavy. On section, they were dry, and contained very little blood, and what they
did was almost all found in the branches of the pulmonary arteries. "It was black-looking blood, thicker than normal, but not by any means so thick as some have described it; nor was it so thick but that, on accidentally puncturing the jugular vein, it escaped in such quantities that the right side of the heart was in one or two minutes completely emp. tied. There was, I think, no reason, as regards its thickness, why the blood should not have circulated through the capillaries." "In other cases, the lungs were congested throughout, of a deep claret colour ; but they weighed less than normal, and the intestines contained ricewater, showing death during the cold stage."

Dr. Sutton goes on to say that "the right side of the heart was full of blood; the jugular veins and cave leading to the right heart were full of blood; the coronary veins were in the same condition. The left side of the heart was contracted, and contained scarcely any blood."

Upon this account of the state of the lungs and heart in the collapse stage of cholera, I venture to remark that it is essentially in agrecment with the account which $I$ have before given of this subject; and in direct opposition to the statements made some months since by two of the medical staff of Guy's Hospital, who simultaneously, in two different medical journals, imputed to me great inaccuracy upon this anntomical question.

With regard to those cases in which the lungs are found congested, but still much below the normal weight, I believe it will be found that they are cases in which death has occurred after very prolonged collapse, or the examination of the body has not been made until several hours after death. I have good reason for my belief, that the tendency to capillary stasis in the lungs is greater in cases of prolonged collapse than in cases which are rapidly fatal; and it is certain that a long interval between death and the examination of the body allows purely mechanical forces to greatly alter the distribution of blood. With regard to the dark colour and the increased consistency of the blood in cholera, it should be borne in mind that this condition of the blood is not peculiar to cholera; but, on the contrary, it occurs more or less in all forms of disease which are associated with a greatly impeded circu. lation through the lungs. Dr. Dundas Thomson found that a specimen of the blood from the nose of a patient who was suffering from "an affection of the mucous membrane of the air-tubes" contained less water in proportion to solids than any specimen of cholera-blood that he had examined. (Mled.-Chir. Trans., vol. xxxiii, p. 74.) Dr. Buchanan of Glasgow, in one of his papers on Tracheotomy in Croup and Diphtheria, remarks that "a quantity of dark tarry-looking blood" flowed from the edges of the wound in a case of diphtheria; and he sug. gests, that this viscidity of the blood, its " tarry consistency", in addition to its dark colour, may be "one of the pathological elements" of diphtheria in an advanced stage. This condition of blood occurs in the apnoeal forms of diphtheria, as a result of defective respiration and the consequent tendency to blood stasis. Slowly moving blood tends to become dark and viscid, and stagnating blood tends to coagulate; so that, in some cases of apnoa-cases of croup, diphtheria, etc. - coagula in the pulmonary artery appear to be the immediate cause of death.

Dr. Sutton thinks that the anæemia and the diminished weight of the lung in the collapse stage of cholera may be due to loss of water. It is difficult to understand in what way a drain of water from the blood can render the lungs light and anæmic, and Dr. Sutton does not explain the mystery. Moreover, he states that, in a case of diphtheria with occlusion of the minute bronchial tubes by fibrinous exudation, he found the lungs as anæmic as in the collapse stage of cholera. I have observed the same appearances in a case of diphtheria. Now it is certain that, in these cases of diphtheria, a drain of water frum the blood is not the cause of the pulmonary anomia ; but, in a paper recently commu. nicated to the Royal Medical and Chirurgical Society, an abstract of which appeared in the BRITISH MEDICAL JovRNAL of Dea 25 ht, I have endee. voured to show that, in cases of acute apnoen whan the air is cuti, off from the lungs, the minute pulmonary arteries arrest the fow of blood. I have there brought forward a number of facts which tend to prove that there is a most interesting correlation between the circulation apd the functions of respiration, secretion, and nutrition; so that the failuae of these functions leads to a retardation, or even a complete arrest of the circulation; the minute arteries, with their muscular walls, acting. 85 stop-cocks in the regulation of the blood-supply to the various tissues.

Dr. Sutton refers to cases which show that there is rather an inverse than a direct relation between the degree of collapse and the amount of liquid discharged from the alimentary canal; and Mr. Simon, in com. menting upon this point, quotes the observations of Dr. Goldbaum (published in Virchow's Archiv, Oct. 1867), "who expressly guards against undue importance being attached in such cases to the quantities of fluid (half or two-thirds of a gallon at the utmost) which may be retained within the patient's intestinal canal; pointing out that the contrast is with cases where perhaps as much as seven gallons are discharged by romiting and purging, and that, consequently, no allowance made for intestinal contents can affect the truth of his proposition, that the cases of worst augury are those that have fallen into collapse after but little or no vomiting and purging." Mr. Simon, while admitting that these facts are difficult to reconcile with the theory that collapse is mainly a result of the drain of fluid, objects that, "in these compara. tive statements, two most important variables have not been taken into the account." These are: $r$, the varied rapidity with which the fluid is poured out; and 2, the varying susceptibility of the individual patient. Now, it cannot be denied that a rapid drain of fluid from the blood, like a rapid hæmorrhage, would produce a greater impression upon the system than a more gradual loss of blood-constituents. It is certain, too, that some individuals are more affected than others by an equal loss of blogd-materials; but, allowing all due weight to these considerations, it is impossible to reconcile the facts of the disease with the hypothesis that a loss of fluid is the main or essential cause of cholera collapse.

The symptoms are not such as loss of fluid, however rapid or copious, has ever been known to produce. The effect of remedies is quite irreconcilable with the hypothesis in question; but, above all, there is this unquestionable fact, that a continuance of these intestinal discharges, which have been supposed to be the cause of collapse, is an essential condition for recovery from collapse. Upon this point, I quote the following from a very able paper by Drs. McCloy and Robertson, in the last volume of the Medico-Chirurgical Transsactions, p. 188. The paper referred to is based upon the observation of 375 cases of cholera and several thousand cases of diarrhoea.

"Whatever the treatment adopted, the result was the same. Reco. very never occurred woithout the continuance of the intestinal discharges, or their resloration, if previously arrested. But, if the collapse of cholera be produced by the drain of fluid from the blood consequent upon these discharges, surely recovery ought to be preceded by their arrest, and not by their continuance. Fatal collapse, on the other hand, invariably followed when the discharges could not be restored. Death may, and very often does, occur without discharges; recovery never. May we not, then, reasonably look upon the discharges as salutary-as the agents by which Nature frees the system from a deadly poison? We believe so; and, with this belief, we can no longer retain that hypothesis which denands their arrest."

Mr. Simon, while admitting the existence of a cholera "contagium", maintains that the operation of the virus is primarily upon the mucous membrane of the alimentary canal, without the intervention of the blood; that the facts of cholera, so far as he knows them, "can all be reconciled with the belief that cholera begins as a bowel-disease, pro-. ducible by direct contagion, without even a passive intervention of the blood; and that all asphyctic phenomena of the disease are supervenient sympathetic phenomena." If I could adopt this.pathological creed, I should find in it one of the most cogent arguments in favour of an eva: cuant practice; for, if the cholera poison were a local irritant, not contaminating the blood, but confined within the alimentary canal, and acting primarily upon its mucous surface, there would surely be good reason to hope that, by the timely exhibition of a prevenient purgative, we might expel the perilous stuff from the bowels, and thus arrest those. "supervenient sympathetic phenomena" which are so terrible to witness, and so difficult to control and to remove.

I will not hore repeat the facts and arguments which $I$ have elsewhere adduced in favour of the proposition that the cholera poison enters the blood before it produces its characteristic local effects. * I will not dwell upon the very serious objection, that Mr. Simon's hypothesis necessa- 
rily assumes that the cholera poison is always swallowed, and never inhaled; but I would ask Mr. Simon, and those who agree with him, to refer to any analogous poison remaining in contact with the alimentary canal, without entering the blood as an essential condition of its poisonous operation, and giving rise to analogous symptoms by a merely nervous sympathy. Mr. Simon does not deny that the blood is poisoned during cholera. In proof that it is so poisoned, he refers to numerous recorded cases in which the intrauterine offspring has been killed by the cholera poison conveyed to it, as Mr. Simon admits, through the maternal blood, and exciting the characteristic rice-water discharges into the alimentary canal. But he asks, "Is there any reason to suppose that the cholera contagium in the mother's blood was not a secondary product of disease-was not let into her circulation from the ferment-seething interior of her bowels?' I would ask, Is there any reason to suppose that there exists such an essential difference between the primary poison which conveys the disease to the mother, and the secondary product which imparts the same disease to her offspring, that, while one is absolutely excluded from the maternal circulation, the other is freely admitted? But the difficulty does not end here. It is manifest that, before the poison can act upon the alimentary canal of the foetus, not only must it have entered the blood of the mother, but it must also have passed through the circulation of her offspring. If it were true, as Mr. Simon believes, that "cholera begins as a bowel-disease, producible by direct contagion, without even the passive intervention of the blood," then the foetus in utero would be absolutely safe from the operation of the poison, which could not, under the assumed conditions, be brought into contact with its alimentary canal. As the intrauterine offspring may die of cholera, so may it die of small-pox, conveyed to it, like cholera, by the maternal blood. What now would be thought of this question, if it were seriously put? Is there any reason to suppose that the small-pox virus in the mother's blood was not a secondary product of disease - was not "let into her circulation from the ferment-seething" surface of her skin? Mr. Simon, by his reference to cases of intrauterine chotera, has afforded valuable confirmatory evidence in favour of the proposition that the cholera poison, in whatever way it enters the system, whether with the air through the lungs, or with the food or water through the alimentary canal, is absorbed into the blood before it gives rise to its characteristic effects.

\section{THERMAL VALUE OF FOOD.*}

By WILLIAM H. O'LEARY,

and Physiology, Ledwich School of Medicine; Surgeon to

\section{Locturer on Anatomy and Physiology, Ledwich School of
St. Vincent's Hospital, Dublin; etc}

THE object of the paper I have the honour of bringing before the Association, is to demonstrate that which must appear patent to every mind from a purely physical point of view - that the food ingested and chemically acted upon in the system (blood ?) is perfectly adequate to account for the various opera required for its ordinary and extraordinary wants. This subject I propose to consider under two heads. I. The food egested in a given time, and an ascertainment of its thermal value. 2. The disposal of its thermal value between the heat consumed in calorifying purposes, and as a mechanical agent.

My experiments extended over a period of six consecutive days, and were performed on myself with a view to obtaining the greater accuracy of result: The first difficulty I experienced was in endeavouring to obtain accurate analyses of the food ingested; but I have spared no labour in collecting the most reliable information on this point.

In the first item of food, eggs, I have availed myself of Gobler's analysis of the yolk. I found great difficulty in obtaining an accurate analysis of the white; but, for this, I have taken Lehmann's results. For butter, I have taken Broun's analysis. Potatoes I had weighed after having been cooked and roasted, containing at time of ingestion about 50 per cent. of water. Milk I used at specific gravity of 1038; in this I have accepted Vernois and Becquerel's results; and, in doing so, Professor Cameron informs me, I am justified, although he differs slightly from them. For the quantity of water in meats, raw and cooked, as well as the water of panification in bread, also the water in vegetables used by me during my experiments, I have availed myself of the results of the Rev. Professor Haughton's investigations, as quoted in the Dublin Quarterly Medical Fournal, August 1859-60.

I deem it unnecessary to give each day's food separately. The following is taken from one of the six days, and will suffice. June 20 th. Eggs, $3 \frac{1}{6}$ oz. ; well dried toast, white bread, 2 oz.; butter, $3 \frac{1}{1}$ oz.; sugar,

\footnotetext{
Medical in the Physiological Section before the Annual Meeting of the British Medical Association in Dublin, August 1867.
}

white, 2 oz.; milk, fl. $4 \mathrm{t}$ oz. ; beef, muscle, 9 oz.; fat of ditto, 1 oz. ; white bread, one day old, $4 \frac{1}{1}$ oz.; bitter ale, fi. 22 oz.; brandy, fl. 2 ; oz.; water, 6 oz.; tea, f. $25 \mathrm{oz}$. The six days' experiment gave an average of, by analysis, carbon 2758.6 grains, hydrogen 405.9 grains, nitrogen 216.2 grains, oxygen 515.2 grains, alcohol 1979.4 grains. The proportion of alcohol in this table looks suspiciously large; but this is accounted for by the fact that, instead of calculating the thermal value of starch and sugar simply by their elements, I ascertained what amount of alcohol they would produce if converted into it, and allowed in my calculations the thermal value which would be rendered by its complete oxidation in the blood. This latter course $I$ have adopted rather than the former, not without due consideration or anticipating objections which may be raised against it.

The determination of the thermal value of the carbon, hydrogen, nitrogen, and oxygen, ingested, is based on the following considerations. The nitrogen, I have presupposed, enters into the formation of urea without necessarily raising the question, whether it is derived exclusively from the tissues, or the food, or both.

To the nitrogen I have assigned quantities" of carbon, hydrogen, and oxygen, in the proportion to form urea; but the carbon entering into combination with it exists in the proportion of $\mathrm{C}^{2} \mathrm{~N}$ (cyanogen); which again has oxygen united with it in the proportion of $\mathrm{C}^{2} \mathrm{NO}$ (cyanic acid); which latter union gives a thermal value equal to the quantity of carbon in combination with it. I, therefore, give to the carbon uniting with nitrogen to form urea such thermal value as if it had been completely oxidised, producing $\mathrm{CO}^{2}$, and exhaled by lungs or skin. To the hydrogen entering into combination with the compound radicle, $I$ do not assign a thermal value; but $I$ am not at all confident that $I$ am justified
in doing so.

By the following table, we can easily calculate the number of grains of carbon, hydrogen, and oxygen, united with the nitroge' ingested; viz., 216 grains to form urea.

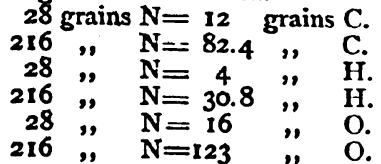

The following table shows the number of grains of carbon, hydrogen, and oxygen available, after disposal of such as unite with nitrogen to form urea.

Total quantity ingested Total excreted as Total quantity remaining
daily in grains.
urea in grains.
C. 2758.6
.......
C 82.4
H 30.8
N 216.2
N 216.2
O 515.2
O 123.0
for further disposal.
C 2758.6
..... II 375.1
...... N nil.
O 393.3

The oxygen ingested, I have assumed, had been already combined with hydrogen and carbon of the food, in the proportion to form water and carbonic acid, in perhaps a rather empirical manner; viz, equal parts of hydrogen and carbon, assigning to them, therefore, no thermal value; but not without some misgiving as to the accuracy of doing so; looking upon the question as a truly important one, not more to the present issue than in a chemical point of view.

The following table shows the number of grains of hydrogen and carbon already in combination with oxygen in the food, which may be calculated thus :

393 grains $\mathrm{O}=49$ equivalents.

49 equivalents $\{24.5$ equivalents $O=24.5$ grains $H$.

This number of grains of cäbon and hydrogen are not available, therefore, as a thermal agent, and must be deducted.
Available after loss by
urea in grains.
$\mathbf{C}+\mathbf{H}$ in union with
$O$ in food.
C 2758.6
H 375.1
.......
C 73.0
H 24.5
O nil.
$\cdots \cdot$
Total available for thermal uses.
C 2685.6
O 393.3
.......
.......
H 350.6

After calculating the number of grains of carbon and hydrogen which enter into the formation of urea, and the quantity already in combination with oxygen in the food, we have a total residuum of 2685.6 grains of carbon, 350.6 grains of hydrogen, and 1979.4 grains of alcohol, available for oxidation, producing thermal results. The value of these $I$ will now reduce to a tangible form; viz., what physicists term thermal units. Each thermal unit represents that amount of heat which is capable of raising one pound of water through one degrec, either centigrade or Fahrenheit, and equally represents mechanical force. Thus, the heat which is capable of raising one pound of water through one degree centigrade is capable of raising $1390 \mathrm{lbs}$. one foot high, or one de- 